\title{
Corrigendum
}

\section{Complement as a multifaceted modulator of kidney transplant injury}

Paolo Cravedi and Peter S. Heeger

Original citation: J Clin Invest. 2014;124(6):2348-2354. doi:10.1172/JCI72273.

Citation for this corrigendum: JClin Invest. 2015;125(3):1365. doi:10.1172/JCI81182.

In the original article, it was incorrectly stated that "Human CD46 (murine homolog Crry), also known as membrane cofactor protein (MCP), has similar decay-accelerating function, but also exhibits cofactor activity." Human CD46 has only cofactor activity; it does not have decay-accelerating activity. The corrected sentences appear below.

Page 2348:

Human CD46, also known as membrane cofactor protein (MCP), exhibits cofactor activity: in conjunction with soluble factor I, this membrane-bound regulator inactivates $\mathrm{C} 3 \mathrm{~b}$ to iC $3 \mathrm{~b}$, thereby preventing reformation of the $\mathrm{C} 3$ convertase. The murine homolog of CD46, Crry, has both cofactor activity and decay-accelerating activity.

The authors regret the error. 